\title{
Endocardial Lead Extraction in the Polish Registry - clinical practice versus current Heart Rhythm Society consensus
}

\author{
Michał Chudzik ${ }^{1}$, Andrzej Kutarski ${ }^{2}$, Przemysław Mitkowski ${ }^{3}$, Andrzej Przybylski ${ }^{4}$, Joanna Lewek ${ }^{5}$, \\ Barbara Małecka ${ }^{6}$, Tomasz Smukowski ${ }^{3}$, Aleksander Maciąg ${ }^{7}$, Janusz Śmigielski ${ }^{8}$
}

\begin{abstract}
'Department of Electrocardiology, Medical University of Lodz, Poland ${ }^{2}$ Department of Cardiology, Medical University of Lublin, Poland ${ }^{3}$ Department of Cardiology, Poznan University of Medical Sciences, Poland ${ }^{4}$ Cardiac Arrhythmias Department, Institute of Cardiology, Warsaw, Poland ${ }^{5}$ Department of Cardiology, Medical University of Lodz, Poland ${ }^{6}$ Department of Electrocardiology, John Paul II Hospital, Krakow, Poland 'Department of Cardiology, Institute of Cardiology, Warsaw, Poland ${ }^{8}$ Department of Statistics, Medical University of Lodz, Poland
\end{abstract}

Submitted: 3 July 2011

Accepted: 6 September 2011

Arch Med Sci 2014; 10, 2: 258-265

DOI: 10.5114/aoms.2013.33434

Copyright @ 2014 Termedia \& Banach

\section{Abstract}

Introduction: Over the last 10 years, there has been an increasing number of patients with pacemaker (PM) and cardioverter-defibrillator (ICD). This study is a retrospective analysis of indications for endocardial pacemaker and ICD lead extractions between 2003 and 2009 based on the experience of three Polish Referral Lead Extraction Centers.

Material and methods: Since 2003, the authors have consecutively retrospectively collected all cases and entered the information in the database. All patients which had indication for lead extraction according to Heart Rhythm Society Guidelines were included to final analyze. Between 2003 and 2005, the data were analyzed together. Since 2006, data have been collected and analyzed annually. Results: In each year, a significant increase in lead extraction was observed. The main indications for LE were infections in $52.4 \%$ of patients. Nonfunctioning lead extraction constituted the second group of indications for LE in $29.7 \%$ of patients. During the registry period, the percentage of class I indications decreased from $80 \%$ in 2006 to only $47 \%$ in 2009 . On the other hand, increasingly more leads were removed because of class 2, especially class 2 b. In $2009,40 \%$ of leads were extracted due to class $2 b$.

Conclusions: Polish Registry of Endocardial Lead Extraction 2003-2009, shows an increasing frequency of lead extraction. The main indication for $L E$ is infection: systemic and pocket. An increase in class 2 , especially $2 b$, LE indication in every center during the study period was found.

Key words: lead extraction indication, abandoned lead extraction, nonfunctional lead extraction.

\section{Introduction}

Over the last ten years, there has been an increasing number of patients with pacemaker (PM) and cardioverter-defibrillator (ICD) implantation. Additionally, there are now lead extraction consensus experts for prolonging a patient's life expectancy, many nonfunctional leads, indications
Corresponding author: Michal Chudzik MD, PhD Department of Electrocardiology Medical University of Lodz 1/3 Sterlinga St 91-425, Lodz, Poland Phone: +48 691941814 E-mail: michalchudzik@wp.pl 
for upgrading systems, and increasingly more complications related and not related to leads [1].

In one of the largest European single-center studies, the most common indication for lead extraction (LE) was local and systemic infection [2]. It was also the most frequent reason for lead extraction, an indication seen in other published studies [3-5]. This is a class 1 indication according to the current Heart Rhythm Society (HRS) consensus. Functional and nonfunctional retained leads that can cause life-threatening arrhythmia were a very rare indication for lead removal. On the other hand, other class 1 indications for lead extraction, venous thrombosis or venous stenosis were not reported in these studies. Class 2 indication was very seldom utilized as an indication for lead extraction. However, none of the authors have analyzed class 2 indications over the study period, which is now becoming increasingly more frequent.

This study is a retrospective analysis of indications for endocardial pacemaker and ICD lead extraction between 2003 and 2009 based on the experience of three Polish referral lead extraction centers (which handle more than $95 \%$ of all lead extractions in Poland).

\section{Material and methods}

Endocardial Lead Extraction is retrospective study. Every one patient with indication for lead extraction according to HRS were included to the final analyses. There was no exclusion criteria. Patients informed consent was signed with patient's agreement for lead extraction. There was no ethic committee because of retrospective analyses of this registry. Since 2003, the authors have consecutively collected details case by case and entered them in the database. At the beginning, i.e., between 2003 and 2005, data were analyzed for the 3-year period. Since 2006, data have been collected and analyzed annually. All indications for lead extraction from 2003 to 2009 were analyzed according to the current Heart Rhythm Society Document: Transvenous Lead Extraction: Heart Rhythm Society Expert Consensus on Facilities, Training, Indications, and Patient Management published in May 2009 [1].

There was no statistical analyses in this study. The data were presented as values of number of the patient classified according to HRS lead extraction class.

\section{Results}

Between 2003 and 2009, there were two main lead extraction (LE) centers - Centers A and B. Since then, the third one, Center $C$, has started to perform LE procedures.

At present, there are three major lead extraction centers in Poland: one high volume center (Center A) that handled 209 patients with lead extraction procedures in 2009 compared to 42 patients and 46 patients in the other two (Centers B and C). During the study, 426 patients (i.e., 67\%) had leads extracted in Center A compared to 153 and 46 in Centers B and C.

From 2006 to 2009, a marked increase in the number of patients with lead extraction (doubling every year) was observed in Center A. A similar number was noted in Centers B and C in 2009.

Figure 1 shows the number of patients with LE procedures in Centers A, B, and C in Poland from 2003 to 2009.

Lead extraction procedure according to the HRS Expert Consensus [1] was defined as the removal of a lead that has been implanted for more than one year or regardless of the duration of the implant requiring the assistance of specialized equipment that is not included as part of the typical implant package and/or removal of a lead from a route other than via the implant vein. ICD leads may require specialized extraction equipment even when the implantation duration is less than 1 year.

Manual, gentle probation traction was used as the first approach for the not-so-old implanted leads only if their mobility in the venous course was confirmed. If this method failed, leads were extracted using dedicated tools such as a standard or locking stylet, dilator sheaths, and modern, more sophisticated systems (Evolution Perfecta, Cook Inc). To disconnect the actively fixed lead from the endocardium, the fixation element was screwed out or the total lead body was rotated under direct fluoroscopy. These maneuvers were followed by extraction of the lead with manual traction. This procedure was suf-

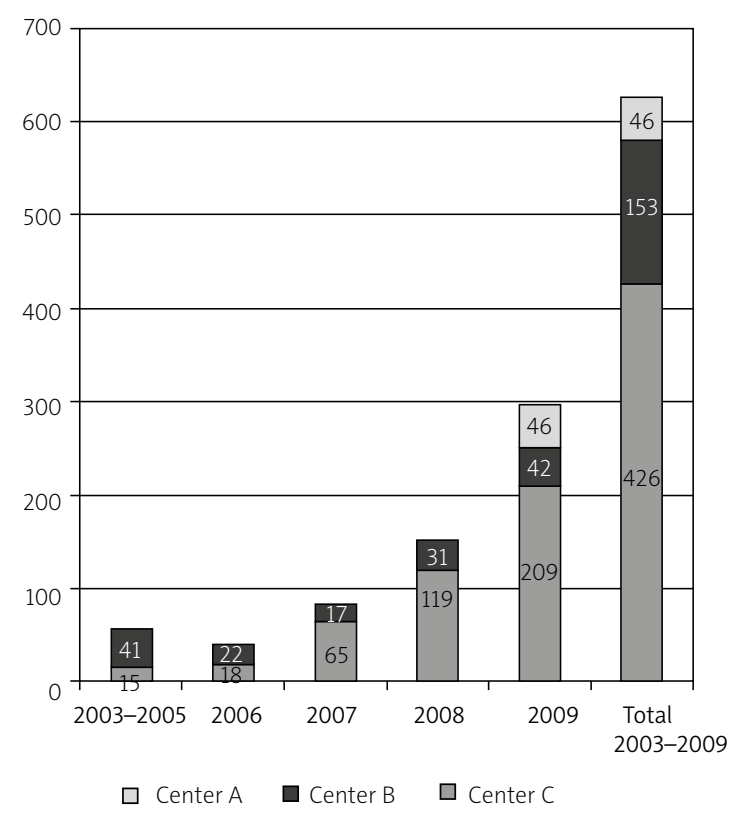

Figure 1. Total number of patients with lead extraction procedures in three centers $A, B$, and $C$ from 2003 to 2009 


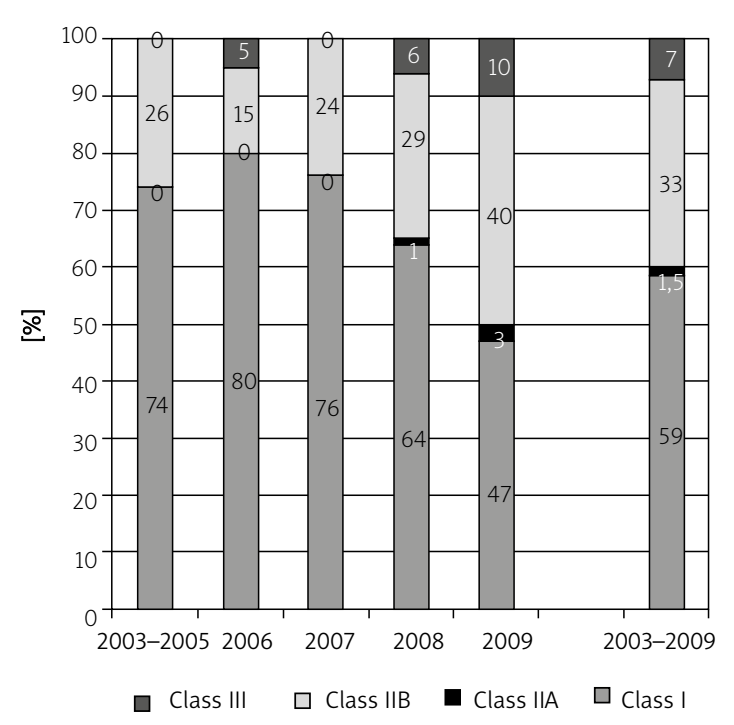

Figure 2. Percentage of patients with lead extraction procedures according to classes of the current Heart Rhythm Society Expert Consensus from 2003 to 2009

ficient only for a small percentage of leads, because other connective tissue and scar tissue surrounding the lead in the atrial or venous course compelled extractors to use additional tools.

The majority (> 90\%) of the leads were usually removed via the same transvenous access by which they were inserted; these were termed the implant vein. During most (>90\%) lead extractions, different dedicated sheaths were utilized; they included polypropylene (rarely Teflon), telescopic Byrd dilators with different diameters (Cook) that served to disrupt fibrotic attachments and metal sheaths for the venous region - entry only. Sometimes, telescoping sheaths or any extraction sheath were used as a single sheath or were paired with a second sheath. The use of two sheaths has advantages such as the flexibility of the inner sheath and the stiffness of the outer sheath to prevent kinking and to improve the effectiveness of advancement over the lead without overstressing the lead. If dilator sheaths were not effective, a decision to use the Evolution Perfecta system (Cook) was made. However, this method was used in less than $4 \%$ of patients. No laser system was used for LE procedures registered in the database. For leads without an accessible ending in previous methods, venous entry was used (dropped-in leads with proximal ending in vein), and for leads accidentally broken during the extraction procedure alternative approaches (jugular, femoral) and other tools (e.g., Femoral Working Station - Cook, lasso catheters, Dotter basket catheters or different snares, and pigtail catheters) were used.

In the three main centers, cardiologists were the primary operator (100\% of procedures). In Centers A and $B, L E$ in the electrophysiology (EP) cath lab was performed with a cardiothoracic surgeon on standby, and in Center C, lead extraction took place in the cardiothoracic operating room. All LE procedures were performed with total intravenous anesthesia.

From January 2003 to December 2009, 625 patients underwent lead extraction procedures. Mean patient age was $59.6 \pm 20$ years (range: $19-86$ years); 386 were male and 239 female.

The main indication for LE was infection in $52.4 \%$ of patients as evidenced by lead-dependent infective endocarditis: sepsis in $14.4 \%$ and pocket infection as evidenced by pocket abscess, device erosion, and skin adherence in $38 \%$.

Nonfunctional lead extraction, which was performed during PM replacement, system revision or upgrading (if contraindications were absent) comprised the second group of indications for LE in $29.7 \%$ of patients. In this group, the most frequent reason for LE was lead failure in $16.7 \%$. Other major reasons for lead removal were ipsilateral venous occlusion preventing access to the venous circulation for the placement of an additional lead, when there is no contraindication for using the contralateral side ( $5 \%$ of patients), and a potentially dangerous lead (risk of threat to the patients if left in place) in $3.6 \%$ of patients. When a functional lead was not used, it was extracted less frequently (i.e., RV pacing lead after upgrade to ICD), in $3 \%$.

Indications for lead extraction according to classes of the Heart Rhythm Expert Consensus are shown in Figure 2.

During the Registry period, the percentage of patients with class 1 indications decreased from $80 \%$ in 2006 to only $47 \%$ in 2009 . On the other hand, more leads were removed in classes $2 a, 2 b$, and even in 3. In 2009, 40\% of patients had LE according to class $2 \mathrm{~b}$ (compared to $15 \%$ in 2006). It is important to note that the percentage of patients with class $2 \mathrm{~b}$ indications was very similar to class I in 2009 (47\% in class 1 and 40\% in class $2 b)$. During the study, $33 \%$ had LE which is in the current class $2 \mathrm{~b}$ of the HRS Expert Consensus.

\section{Class 1: HRS Expert Consensus}

Indications for class 1 lead extraction in the Polish Registry from 2003 to 2009 are shown in Table I.

For the last 6 years, pocket infection has been the main indication in class 1 for lead removal; however, there has been a decrease in the percentage of patients with this complication with indications for $L E$ (65\% in 2006 and 27\% in 2009). Although the number of patients with systemic and pocket infections has been increasing every year, the percentage of patients with LE was stable in systemic infection and even decreased in pocket infection.

\section{Class 2: HRS Expert Consensus}

During the last 5 years, an increase in the number of patients with lead extraction according to class 2 was observed. In 2009, half of the patients with lead 
Table I. Number of patients with lead removal in class I in the Polish Registry, 2003-2009

\begin{tabular}{|c|c|c|c|c|c|c|}
\hline \multirow[t]{2}{*}{ Variables } & \multicolumn{5}{|c|}{ Year } & \multirow{2}{*}{$\begin{array}{c}\text { Total } \\
2003-2009\end{array}$} \\
\hline & 2003-2005 & 2006 & 2007 & 2008 & 2009 & \\
\hline Systemic infections & 6 & 4 & 15 & 27 & 37 & 89 \\
\hline Pocket infections & 33 & 26 & 45 & 60 & 79 & 243 \\
\hline $\begin{array}{l}\text { Ipsilateral venous occlusion preventing access to the venous } \\
\text { circulation for required placement of an additional lead when } \\
\text { there is a contraindication for using the contralateral side }\end{array}$ & 0 & 0 & 0 & 3 & 3 & 6 \\
\hline Superior vena cava stenosis or occlusion with limiting symptoms & 0 & 0 & 0 & 0 & 2 & 2 \\
\hline Possibility of immediate threat to the patients if left in place & 2 & 1 & 1 & 5 & 13 & 22 \\
\hline Life-threatening arrhythmias secondary to retained leads & 0 & 0 & 1 & 0 & 1 & 2 \\
\hline Interference with the operation of implanted cardiac devices & 0 & 0 & 0 & 1 & 2 & 3 \\
\hline $\begin{array}{l}\text { Interference with the treatment of a malignancy } \\
\text { (radiation/reconstructive surgery) }\end{array}$ & 0 & 1 & 0 & 0 & 1 & 2 \\
\hline $\begin{array}{l}\text { Total number of patients with leads extracted in class I } \\
\text { of HRS Expert Consensus in Polish Registry 2003-2009 }\end{array}$ & 41 & 32 & 62 & 96 & 138 & 369 \\
\hline
\end{tabular}

removal were in class 2 recommendation in Center $A$ (Figure 2). A similar very high percentage of class 2 recommendation in 2009 in Centers B and C was noted. Figure 3 shows the number of patients with lead extraction procedures according to class 2 indications during the Registry period in all centers.

\section{Class 2 indications in Polish pacemaker and ICD endocardial lead extraction registry}

Some years ago, the authors tried to introduce more detailed indications for lead extraction to the computerized database. Common practice showed that in a lot of patients the lead was extracted due to several reasons simultaneously. The authors tried to select the most important criterion, but finally the obtained results can indicate a tendency only. The most important subgroup of reasons why the decision about LE was undertaken included malfunction of a previously functional lead (broken conductor, lead isolation or connector) in $49.4 \%$ of patients, too many leads in patients with a long life expectancy but not a HRS criterion (functional and nonfunctional leads) in $7.2 \%$, too many leads in patients who fulfilled the HRS criterion (functional and nonfunctional leads) in $2.5 \%$, change of pacing mode, upgrading (functional and sometimes nonfunctional lead) in $8.9 \%$, nonfunctional PM lead (high pacing threshold, undersensing, dislodgement, extracardiac pacing, atrial lead, and permanent AF) in $19.8 \%$, nonfunctional ICD lead (damaged, high pacing threshold, undersensing, dislodgement) in patients with a long life prognosis in $5.5 \%$, children and young patients with strained nonfunctional lead or other lead that should be abandoned in $6.7 \%$.

\section{Class 2 in 2009}

The authors stress that among class 2 indications for lead extraction, class $2 \mathrm{~b}$ constitutes the majority.

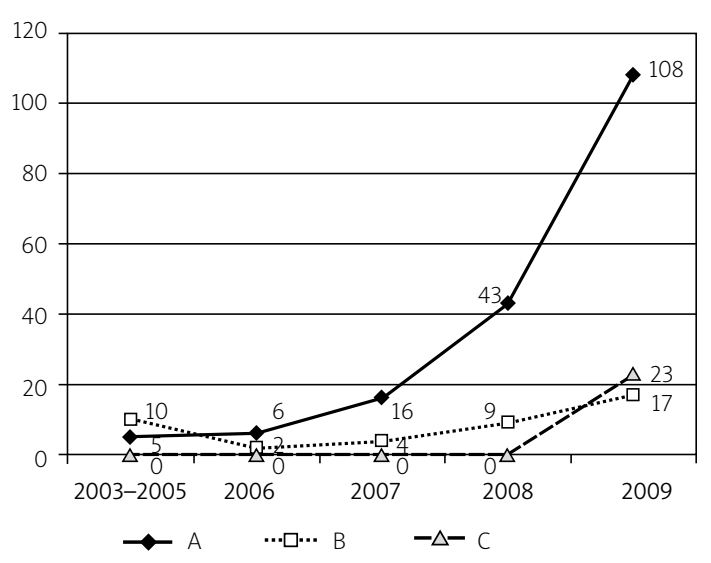

Figure 3. Number of patients with lead extraction in three centers according to the current class II HRS recommendation in the Polish Registry, 2003-2009

The percentage of patients with lead removal in class $2 \mathrm{~b}$ ranged from $32 \%$ in Center C to $42 \%$ in Center $\mathrm{A}$. Class $2 \mathrm{~b}$ showed a much more frequent indication compared to class $2 a$, independent of the centers. The percentages of patients with lead extraction in 2009 in classes $2 a$ and $2 b$ in centers $A$, $B$, and $C$ were as follows: Center $A-11 \%$ and $40 \%$; Center $\mathrm{B}-5 \%$ and $36 \%$, Center $\mathrm{C}-8 \%$ and $32 \%$.

The most common class $2 \mathrm{~b}$ indication for lead extraction was lead failure in all centers, although Center $B$ accounted for $80 \%$ of $2 \mathrm{~b}$ class indications. In Centers A, B and C, nonfunctional leads were the most frequent reason for extraction. None of the leads were extracted (functional and nonfunctional) because a specific imaging technique was required (e.g., MRI).

A summary of indications in class $2 b$ in 2009 is shown in Table II.

Use of the opposite chest side and abandonment of leads in the previously used chest side is not popular in Poland. Recently, the authors prefers 
Table II. Number of patients with class IIB indications for lead removal in class IIB in three centers in 2009

\begin{tabular}{|c|c|c|c|}
\hline Number of patients with class IIB indication & Center A & Center B & Center C \\
\hline \multicolumn{4}{|l|}{ Functional lead } \\
\hline $\begin{array}{l}\text { Lead removal may be considered in patients with an abandoned functional lead that poses } \\
\text { a risk of interference with the operation of the active CIED system }\end{array}$ & 5 & 0 & 8 \\
\hline $\begin{array}{l}\text { Lead removal may be considered in patients with leads that are functional but } \\
\text { not being used. (i.e., RV pacing lead after upgrade to ICD) }\end{array}$ & 8 & 0 & 0 \\
\hline $\begin{array}{l}\text { Lead removal may be considered in patients who require specific imaging techniques } \\
\text { (e.g., MRI) that cannot be imaged due to the presence of the CIED system for which there } \\
\text { is no other available imaging alternative for the diagnosis }\end{array}$ & 0 & 0 & 0 \\
\hline \multicolumn{4}{|l|}{ Nonfunctional leads } \\
\hline $\begin{array}{l}\text { Lead removal may be considered at the time of an indicated CIED procedure, in patients } \\
\text { with nonfunctional leads, if contraindications are absent }\end{array}$ & $\begin{array}{c}71 \\
\text { Lead } \\
\text { fracture } \\
-47(56 \%)\end{array}$ & $\begin{array}{c}15 \\
\text { Lead } \\
\text { fracture } \\
-12(80 \%)\end{array}$ & $\begin{array}{c}21 \\
\text { Lead } \\
\text { fracture } \\
-12(57 \%)\end{array}$ \\
\hline Lead removal may be considered to permit the implantation of an MRI conditional CIED system & 0 & 0 & 0 \\
\hline Total number of patients with class IIB indications in three centers in 2009 & & 128 & \\
\hline
\end{tabular}

not to use ipsilateral side during lead implantation. The authors preferred to save the collateral side for other medical utilities (AV fistula for hemodialysis, permanent catheter, or implantation of a new system in case of infection).

Class 2b, i.e., "nonfunctional leads", is a very heterogeneous group. It must be stressed that the following groups of patients with very different "lead complications" belong to this group: patients with lead damage (a lot of symptomatically damaged Sprint Fidelis comprise this subgroup), lead dislodgement, elevated or high pacing threshold, permanent AF with sinus rhythm failed with atrial lead, intramural penetration/transmural perforation, two ICD leads, two or more endocardial leads, and a growing child with strained nonfunctional lead.

Hence, it can be seen that each of the aforementioned groups of patients with nonfunctional leads can cause a new, huge clinical challenge. However, in some patients, there is "only" a $2 b$ indication in a high percentage of leads extracted in clinical practice, which shows that sometimes the guidelines - even current ones - might be followed in clinical practice.

It is also important to note that the high percentage of class $2 b$ LE, which ranges from $32 \%$ to $40 \%$ (Table II), is independent of the center. This also proves to be a real clinical problem.

\section{Class 3: HRS Expert Consensus}

In class 3, the main indication for lead extraction was the anomalous placement of leads through structures other than normal venous and cardiac structures. There were $10(1.6 \%)$ such indications in the registry -6 in Center A, 1 in B, and 3 in C. The procedures performed were ex-atrial/ventricular wall perforating leads and extractions of leads erroneously permanently implanted via the atrial septum (atrial septal defect (ASD), patent foramen ovale (PFO)) into the left ventricle cavity. The procedures were performed under special safety precautions including cardiosurgery standby and carotid artery protection.

There were two main classes of lead extraction indications in 2009 in all centers: classes 1 and 2b. Class 1 showed a decrease in the percentage of procedures during the last 6 years. On the other hand, a huge increase in class $2 \mathrm{~b}$ indications was noted. The main reason for lead removal in this class was nonfunctional lead removal at the time of an indicated cardiovascular implantable electronic device (CIED) procedure, if contraindications are absent. The most frequent reason for lead extraction in $128 \mathrm{pa}-$ tients in class 2b in 2009 was lead fracture in 71 patients (55\%). The number of and expected LE/million/year are shown in Table III.

\section{Discussion}

In the Polish Registry of 619 patients from 2003 to 2009 , lead extractions were performed in three main centers - two of them started procedures over 6 years ago, the last one in 2009. Since the beginning of the study, an increase in the numbers of patients with lead extractions has been noted. The main indication since 2003 has been infection; however, a decrease in the percentage of such procedures during the registry period was observed. On the other hand, an increasing number of class $2 b$ indications was noted during the registry period, 2003-2009. The main reason for LE in class IIB was lead damage.

Most frequently, the leads were extracted due to different forms of damage; this group contains patients with a damaged ICD lead (Sprint-Fidelis predominantly), damaged PM leads in relatively young patients with long-term life expectancy, and 
Table III. Number of lead extractions and expected lead extractions per million for 1 year

\begin{tabular}{|lccccc|}
\hline Variables & \multicolumn{4}{c|}{ Years } \\
\cline { 2 - 5 } & $2003-2005$ & 2006 & 2007 & 2008 & 2009 \\
\hline Number of LE & 56 & 40 & 82 & 150 & 297 \\
\hline Number of implantations (ICD\&PM)/million/year & 479 & 571 & 681 & 769 & 871 \\
\hline LE/million/year & 1.4 & 1.0 & 2.0 & 3.8 \\
\hline Expected LE/million/year (1.5-6.0\% of implantations) & $7.2-28.7$ & $8.6-34.3$ & $10.2-40.9$ & $11.5-46.1$ & $13.1-52.3$ \\
\hline
\end{tabular}

patients with subclavian/anonymous vein occlusion or stenosis and doubtful success of a further lead implantation. The HRS criterion of too many leads is fully acceptable for old patients with midterm survival prognosis. A lot of procedures of dramatic extractions of chronically implanted (1015-20 and more years ago) were performed. Such LE procedures with old leads are very difficult. That is why in the case of abandoned leads in patients it would be much better to extract leads now than in the future. Sometimes, only one superfluous abandoned lead may cause unforeseeable problems in the future, including vein occlusion, mutual lead abrasions and interference, proximal ending lead migration-related problems, and probably primary (unrelated to pocket infection) lead-dependent endocarditis, which is more frequent in patients with multiple leads. Every year, abandoned lead extractions are becoming more difficult and more risky. The authors' clinical experience with lead extraction is much older than the common computerized database and inclined them to believe in the general rule: "to leave behind as few abandoned leads as possible". This was especially so in young/middleaged patients because after a few years, in case of trouble the authors would receive this patient once again, but with more strongly ingrown leads.

In all three centers, the minimum annual number of extractions recommended in the published expert consensus (i.e., 20 leads annually) was achieved [1].

Erven's et al. [6] study showed that in $40 \%$ of centers, lead extraction was performed annually in fewer than 10 patients. In the Polish Registry, even in the new center C, which started procedures in 2009, lead extraction was performed in 46 patients. Such practice might lead to a high success rate for procedures with low risk of unnecessary complications.

The patients had the possibility to be referred to a high volume extraction center, nationally identified with the highest operator skills. It was confirmed in other studies that the risks of a device-assisted lead extraction decrease with the experience of the physician performing the procedure [4, 7-9].

The recently published consensus of Heart Rhythm Society members found that just $18 \%$ of physicians perform more than 50 extractions a year. The Heart Rhythm Society's recent expert consensus panel also emphasized that the steepest decline in lead extraction complication rates occurs during the ope- rator's first 30 cases and that the decline continues up to 400 cases [1].

In Poland, cardiologists are the only operators and procedures in the two main centers are performed in the EP cath lab room. In the published study [6], in some centers, a cardiothoracic surgeon is present during procedures, and in a European survey [6] the surgeon was the main operator in $34 \%$ of cases. Henrikson's et al. published data on behalf of the HRS expert consensus revealed that $25 \%$ of extraction procedures are done without a surgeon or an operating room on standby [10].

In Poland, the main tool for lead extraction is the mechanical tool represented by Byrd dilators (Cook). In none of the centers was the most modern way of $L E$, with a laser extraction device, performed. Byrd [11] reported the first excimer laser-assisted pacemaker lead extraction in 1996. The multicenter randomized pacing lead extraction with the excimer sheath (PLEXES) trial found that laser-assisted extraction was more efficacious than non-laser techniques in 301 patients with no statistically significant difference in life-threatening complications between the laser and the non-laser groups [12]. However, a subsequent nonrandomized European multicenter study of excimer laser-assisted pacemaker and ICD lead extractions in 292 patients reported a 5.1\% complication rate [13].

Byrd [14] and Schaerf et al. [15] have reported their experiences with the mechanical dilator sheath that included 182 pacemaker and ICD leads that were removed by them without any fatality. Also in the experiences of the authors of the present study, laser is not obligatory for effective and non-complicated LE procedures [3, 16].

According to the literature, a polypropylene or Teflon dilator sheath approach is safe and effective.

In most centers, only leads associated with systemic infection were indicated for extraction before the 1990s [2]. During this time period, most leads extracted were removed surgically. Manual traction or a simple device traction method was often found to be unsuccessful and might lead to complications. Before the current 2009 HRS consensus, the North American Society Pacing and Electrophysiology (NASPE) policy statement was published in 2000 [17], in which pacemaker or ICD-related sepsis or endocarditis is a class 1 indication for lead extraction and localized pacemaker or ICD-related infec- 
tions are considered as class 2 indications for lead extraction. In Bracke's et al. study [18], no other indication for lead removal was assessed. According to Kennergren et al. [2], the main indication for LE was infection - only in $59 \%$ of patients. These data are similar to the Polish Registry (in $47 \%$ of patients infection was the indication for LE). Also in the European Survey published in Europace [6], infection is the most frequent indication. Other papers on lead extraction show the same percentage of this indication $[4,19,20]$. However, in the study by Calvagna et al. and Bongiorni et al., infection was an indication for lead extraction in a higher number of patients [21, 22].

Subsequently, transvenous lead extraction methods were developed. At the beginning of this century, telescoping mechanical sheaths and locking stylets as well as laser-assisted lead extraction were widely introduced in clinical practice. Other factors responsible for the increasing number of lead extractions were the increasing number of devices in patients, better life expectancy, new indications, new types of devices, as well as device and lead recalls despite improved lead performance. These new facts led to the increase in non-class 1 indications.

In Kennegren's et al. study [2], class 2 was an indication for lead extraction in $32 \%$ of patients. In both Kennegren's et al. study and the Polish registry, an increasing number of class 2 indications were noted. In Bracke's study [23], the complication rate from extraction was considered before the procedure. Also in patients with venous occlusion and in asymptomatic patients the decision about lead removal should be first properly explored and discussed with the patient because of the risk of potential complications.

In Wollmann's et al. study [24], which compared implantation of new, additional ICD leads and extraction of defective leads and implantation, no higher incidence of complications was found especially concerning oversensing or inappropriate shocks - in the non-extraction group.

The registry, similar to the experience of the Swedish center, shows that in the next few years more class 2 lead removal indications can be expected [2]. On the other hand, the complication rate will decrease mainly because of better lead removal tools and higher volume center experience. All these factors will help in extraction of leads, especially superfluous ones.

In class 2a, in patients with ipsilateral venous occlusion, which prevents access to the venous circulation, an additional lead along with the old LE is reasonable.

It should be mentioned that using the contralateral side in patients with one-side occlusion might lead to dangerous both-side venous thrombosis. Numerous reports of venous complications such as stenosis, occlusions, and superior vena cava syndrome have been published. Some studies have suggested risk factors for vein stenosis: infection, presence of a temporary wire before implantation. Others show that despite 40 years of experience with transcutaneous implanted intravenous pacing systems and dozens of studies, it was not possible to identify clear risk factors (confirmed by independent studies) for venous stenosis or occlusion.

A few factors were proposed as predictors of severe venous stenosis/occlusion: presence of multiple pacemaker leads (compared to a single lead), use of hormone therapy, personal history of venous thrombosis, the presence of a temporary wire before implantation, previous presence of a pacemaker (ICD as an upgrade), and the use of dual-coil leads. That is why a decision during new lead implantation about "NOT removing the old lead" should always be made by an experienced electrophysiologist or an invasive cardiologist. In the majority of studies, venous obstruction in patients with PM or ICD leads was found in up to $30 \%$ of cases $[25,26]$.

Also in nonfunctional lead, its removal may be considered at the time of an indicated new procedure (PM or ICD implantation/reimplantation), if contraindications are absent.

At this moment, class $2 \mathrm{~b}$ with nonfunctional leads compromises more patients. In the registry, more than $30 \%$ of LE were just in class 2.

Extraction of nonfunctional leads - at present in class $2 b$ - is not mandatory and careful evaluation has to precede the decision. However, in some patients in class $2 \mathrm{~b}$, lead extraction should be considered, especially in young patients with long-term life expectancy in whom superfluous lead removal after 10 or 20 years might be much more difficult and dangerous when compared to earlier approaches. Late removal of such leads is strenuous, with long $X$ ray exposure and a long procedure time [28]. In the same class $2 b$ of lead extraction, potential risk of venous occlusion, endocarditis due to lead isolation abrasion, and other and abandoned leads should be carefully estimated before operation.

For many cardiologists, the abandoned lead is always the nucleus for vascular obstruction or infection [27]. An abandoned lead causes increased risk of arrhythmia and in ICD patients may lead to inappropriate shocks.

These $2 b$ indications should not allow the experts to take a quick decision about implantation of a new lead without old lead extraction. Also in nonfunctional leads, the decision about LE should be much more justified compared to functional leads, because these leads will no longer be used, which increases the risk of complications.

This study shows how many procedures are performed due to class $2 b$ indications (nonfunctional leads).

Guidelines, although current, are not followed in clinical practice and always a decision in class $2 b$ should be considered very carefully. 
In conclusion, the Polish Registry, 2003-2009, shows an increasing number of lead extractions with high volume centers having acceptable numbers of LE performed annually by physicians. The main indication for LE is infection: systemic and pocket. Increasingly in class 2 , especially $2 \mathrm{~b}$, LE indication in every center during the study period was found.

\section{Acknowledgments}

We want to thank Maciej Sterliński, Paweł Syska, Artur Oręziak, Jacek Różański, Krystian Stanek, Zofia Sarnowska, Marek Jemielity, Romuald Ochotny for the cooperation in the collection of the material.

Conflict of interest: Dr Michal Chudzik is on the BIOTRONIK Poland Advisory Board.

\section{References}

1. Wilkoff BL, Love CJ, Byrd CL, et al. Transvenous lead extraction: Heart Rhythm Society expert consensus on facilities, training, indications, and patient management. Heart Rhythm 2009; 6: 1086-104.

2. Kennergren C, Bjurman C, Wiklund R, Gabel J. A singlecentre experience of over one thousand lead extractions. Europace 2009; 11: 612-7.

3. Kutarski A, Małecka B, Ruciński P, Zabek A. Percutaneous extraction of endocardial leads - a single centre experience in 120 patients. Kardiol Pol 2009; 67: 149-56.

4. Jones SO, Eckart RE, Albert CM, Epstein LM. Large, singlecenter, single-operator experience with transvenous lead extraction: outcomes and changing indications. Heart Rhythm 2008; 5: 520-5.

5. Field ME, Jones SO, Epstein LM. How to select patients for lead extraction. Heart Rhythm 2007; 4: 978-85.

6. Van Erven L, Morgan JM; the Scientific Initiatives Committee (SIC). Attitude towards redundant leads and the practice of lead extractions: a European survey. Europace 2009; 11: 612-7.

7. Smith HJ, Fearnot NE, Byrd CL, Wilkoff BL, Love CJ, Sellers TD. Five years' experience with intravascular lead extraction. Pacing Clin Electrophysiol 1994; 17: 2016-20.

8. Byrd CL, Wilkoff BL, Love CJ, et al. Intravascular extraction of problematic or infected permanent pacemaker leads: 1994-1996. Pacing Clin Electrophysiol 1999; 22: 1348-57.

9. Byrd CL, Wilkoff BL, Love CJ, Sellers TD, Reiser C. Clinical study of the laser sheath for lead extraction: the total experience in the United States. Pacing Clin Electrophysiol 2002; 25: 804-8.

10. Henrikson CA, Zhang K, Brinker JA. Lead extraction practice in the United States. J Am Coll Cardiol 2009; 53: A129.

11. Byrd CL Extracting chronically implanted pacemaker leads using the Spectranetics excimer laser: initial clinical experience (Abstract). Pacing Clin Electrophysiol 1996; 19: 567.

12. Wilkoff BL, Byrd CL, Love CJ, et al. Pacemaker lead extraction with the laser sheath: results of the pacing lead extraction with the excimer sheath (PLEXES) trial. J Am Coll Cardiol 1999; 33: 1671-6.

13. Kennergren C, Bucknall CA, Butter C, et al. Laser assisted lead extraction: the European experience. Europace 2007; 9: 651-6.

14. Byrd CL. Experience with the new Cook evolution lead extraction sheaths. Heart Rhythm 2008; 5: S30.
15. Schaerf RHM, Norlander BE, Goode L. Clinical experience with the evolution mechanical dilator sheath set for intravascular lead extraction at a single center. Heart Rhythm 2008; 5: S338.

16. Przybylski A, Syska P, Oręziak A, et al. Usefulness of the evolution mechanical dilator sheath for endocardial lead extraction - preliminary results. Postep Kardiol Inter 2010; 6: 59-65.

17. Love CJ, Wilkoff BL, Byrd CL, et al. Recommendations for extraction of chronically implanted transvenous pacing and defibrillator leads: indications, facilities, training. North American Society of Pacing and Electrophysiology Lead Extraction Conference Faculty. Pacing Clin Electrophysiol 2000; 23: 544-51.

18. Bracke FA, Meijer A, Van Gelder LM. Lead extraction for device related infections: a single-centre experience. Europace 2004; 6: 243-7.

19. Field ME, Jones SO, Epstein LM. How to select patients for lead extraction. Heart Rhythm 2007; 4: 978-85.

20. Bracke FA, Meijer A, van Gelder B. Extraction of pacemaker and implantable cardioverter defibrillator leads: patient and lead characteristics in relation to the requirement of extraction tools. Pacing Clin Electrophysiol 2002; 25: 1037-40.

21. Bongiorni MG, Soldati E, Zucchelli G, et al. Transvenous removal of pacing and implantable cardiac defibrillating leads using single sheath mechanical dilatation and multiple venous approaches: high success rate and safety in more than 2000 leads. Eur Heart J 2008; 29: 2886-93.

22. Calvagna GM, Evola R, Scardace G, Valsecchi S. Singleoperator experience with a mechanical approach for removal of pacing and implantable defibrillator leads. Europace 2009; 11: 1505-9.

23. Bracke FA. Yes we can! But should we? Lead extraction for superfluous pacemaker and implanted cardioverterdefibrillator leads. Europace 2009; 11: 546-7.

24. Wollmann CG, Bocker D, Löher A, et al. Two different therapeutic strategies in ICD lead defects: additional combined lead versus replacement of the lead. J Cardiovasc Electrophysiol 2007; 18: 1172-7.

25. Rozmus G, Daubert JP, Huang DT, Rosero S, Hall B, Francis C. Venous thrombosis and stenosis after implantation of pacemakers and defibrillators. J Interv Card Electrophysiol 2005; 13: 9-19.

26. Lickfett L, Bitzen A, Arepally A, et al. Incidence of venous obstruction following insertion of an implantable cardioverter defibrillator. A study of systematic contrast venography on patients presenting for their first elective ICD generator replacement. Europace 2004; 6: 25-31.

27. Zartner PA, Wiebe W, Toussaint-Goetz N, Schneider MB. Lead removal in young patients in view of lifelong pacing Europace 2010; 12: 714-8. 